\title{
Cruzando El puente del troll, de Neil Gaiman: de la literatura al cómic
}

\author{
Álvaro Pina Arrabal ${ }^{(1)}$
}

\begin{abstract}
Resumen: En este trabajo se estudia la adaptación de la literatura al cómic a partir del caso concreto de El puente del troll, un relato de Neil Gaiman que Colleen Doran ha ilustrado más de veinte años después de la publicación del primero. En primer lugar, se contextualiza el fenómeno de la adaptación como parte de un entramado socioeconómico en el que ambas producciones (adaptada y adaptación) se retroalimentan. Se hace, no obstante, especial hincapié en distinguir los rasgos de un medio y los del otro incluso cuando el cómic de Doran vierte el texto original de Gaiman de manera íntegra. En segundo lugar, se atiende a los rasgos intersemióticos que se desprenden de la adaptación, a fin de examinar la transposición de los distintos elementos de un medio al otro. Así, se presta especial atención a la yuxtaposición de la palabra y la imagen, a la metáfora y, sobre todo, a la transmisión de las emociones en el marco de una fábula de carácter alegórico. Se concluye que el trasvase semiótico pleno es inviable en la medida en que se trata de dos medios distintos, si bien los constituyentes de la ficción (historia, personajes, escenarios) son en esencia los mismos.
\end{abstract}

Palabras clave: Adaptación - Intersemiótica - Fantástico - Emociones - Metáfora.

[Resúmenes en inglés y portugués en las páginas 116-117]

(1) Soy graduado en Estudios Ingleses (2015) y Filología Hispánica (2019) por la Universidad de Jaén, donde también he cursado el Máster de Profesorado de Educación Secundaria Obligatoria y Bachillerato, Formación Profesional y Enseñanza de Idiomas (2016) y el Online Master in English Studies (2018). Actualmente realizo mi tesis doctoral en Lenguas y Culturas sobre el autor norteamericano Russell Edson, en el área de Teoría de la literatura y literatura comparada de la Universidad de Jaén bajo el magisterio de la catedrática Genara Pulido Tirado. He publicado el artículo "El influjo de H. P. Lovecraft en la obra de Junji Ito" (2019) en Brumal. Revista de estudios sobre lo Fantástico, y participado en más de una docena de congresos y seminarios académicos. 


\section{Neil Gaiman y "El puente del troll”}

Polifacético y prolífico como pocos, Neil Gaiman (1960) es uno de los artistas en activo más reconocidos en el ámbito de lo fantástico; basta examinar la amplia nómina de premios que acumula para percatarse de ello: tres Premios Harvey, quince Premios Locus, un Premio Inkpot, cuatro Premios Bram Stoker, seis Premios Hugo, dos Premios Nebula, quince Premios Eisner, cuatro Premios Británicos de Fantasía, dos Premios Shirley Jackson o un Premio Mundial de Fantasía, entre otros cuantos. Desde que en 1984 publicó su primera historia corta ("Featherquest"), el autor británico no ha parado de escribir cuentos, poemas y novelas (especialmente conocidas son Neverwhere [1996], American Gods [2001] o Coraline [2002]), así como numerosos guiones cinematográficos y de cómics; en este último caso, es canónica la serie The Sandman, publicada entre 1988 y 1996 e ilustrada por un gran número de artistas de diferentes estilos. No bastante, Gaiman ha participado también en recitales literarios y realizado diversas colaboraciones de radio e incluso de videojuegos (como en el caso de Wayward Manor, 2013). Del mismo modo, son numerosas las adaptaciones elaboradas a partir de obras del artista; por ejemplo, las películas de Stardust (Vaughn, 2007) y Coraline (Selick, 2009) están basadas en las novelas homónimas de Gaiman, así como las series de televisión American Gods y Good Omens, la pieza teatral The Ocean at the End of the Lane (2019) o el radioteatro Neverwhere (2013). El objeto de estudio de este trabajo es, sin ir más lejos, una adaptación al cómic de una de las historias cortas del escritor: "Troll Bridge".

Gaiman concibió este relato para una antología de Ellen Datlow y Terri Windling, titulada Snow White, Blood Red y publicada en 1993, que incluía nuevas versiones de cuentos clásicos a cargo de numerosos autores. Cinco años después, la historia fue incluida en Smoke Mirrors: Short Fictions and Illusions (1998), un libro en el que se recopilan exclusivamente textos, procedentes de distintas fuentes, de Neil Gaiman. El cuento de "Troll Bridge", sin embargo, ha pasado bastante desapercibido para el gran público -como casi cualquier texto literario hoy día- hasta que Colleen Doran, fecunda y reconocida ilustradora que ya había producido el arte gráfico para algunas de las historias más celebradas del autor británico (véase la precitada The Sandman), ha realizado en solitario la adaptación a cómic del relato: Troll Bridge (2016). La utilización aquí de la cursiva para referir a la adaptación al cómic, frente a las comillas empleadas para aludir al relato exclusivamente escrito, no es casual, pues entendemos que la primera conforma un producto más incluyente que incluido y que, por lo tanto, ha de marcarse con cursiva. Se profundizará en esta cuestión en el primer apartado del artículo.

El objetivo fundamental del presente trabajo es analizar la adaptación de la literatura al cómic en el caso particular de Troll Bridge. Para ello, el estudio se divide en dos bloques principales: "Literatura, cómic y adaptación” y “Cruzando El puente del troll". En el primer apartado, se indican los presupuestos teóricos desde los que se plantea la investigación y se contextualiza la adaptación como un fenómeno social y cultural que condiciona la obra y su recepción. En el segundo punto, se atiende a algunos de los rasgos (inter)semióticos que se desprenden del tránsito del relato escrito por Gaiman al cómic ilustrado por Doran, a fin de valorar la transposición de los distintos elementos de un medio al otro. 


\section{Literatura, cómic y adaptación}

Las dos artes comparadas en este artículo son la literatura y el cómic. Se impone, por tanto, la necesidad de definir claramente una y otra con el fin de establecer unas bases comparativas operatorias tanto en la semejanza como, sobre todo, en la diferencia (pues sin esta el comparatismo es inviable). Por un lado, partiendo de muchos de los presupuestos expuestos por Jesús G. Maestro (2014), aquí se considerará la literatura como un sistema estético y ficcional de ideas que se configura mediante signos del sistema lingüístico con carácter autónomo y autosuficiente, y "cuyas figuras fundamentales son el autor, la obra, el lector y el intérprete o transductor" (Maestro, 2014, p. 62). Así, en este caso, la obra literaria es el relato "Troll Bridge", cuyo autor es Neil Gaiman. El lector es toda aquella persona que, haciendo uso de sus capacidades lingüísticas, consume la obra -el empleo del verbo consumir es deliberado, como se explicará más abajo-y que, acaso, la interpreta con base en psicologismos e impresiones personales (lo que, siguiendo el Materialismo Filosófico de Gustavo Bueno, Maestro [2014, p. 50] cataloga como $\mathrm{M}_{2}$ ). En última instancia, la transducción (concepto originalmente acuñado por Doležel, 1986) hace referencia a la interpretación del texto mediante criterios lógicos, racionales y normativos a fin de categorizar y sistematizar las ideas en él objetivadas.

Por otro lado, el cómic puede definirse en términos análogos a los de la literatura si se postula un par de salvedades: 1) a los signos del sistema lingüístico (que son opcionales) cabe añadir el factor -inherente e inalienable- de la imagen en forma de dibujo; sin este, el cómic no es posible; 2) el concepto de autor, que en el caso de la literatura admite tan solo una variación cuantitativa (autor o autores), en el cómic comprende-como poco-las figuras del guionista y del dibujante, que pueden coincidir en el mismo sujeto operatorio (en términos de Materialismo Filosófico) o no. Ambas artes -literatura y cómic- se construyen, como se ha indicado, con carácter autónomo y autosuficiente, lo que conlleva implicaciones ontológicas esenciales a la hora de estudiar la adaptación.

En palabras de Linda Hutcheon (2006, p. 16), las adaptaciones -especialmente aquellas que implican un cambio de medio- son "intersemiotic transpositions from one sign system (for example, words) to another (for example, images)". En el caso concreto de Troll Bridge, se trata de una adaptación en la que el texto del relato original de Neil Gaiman ha sido trasladado íntegramente a los cuadros de texto del cómic; en otras palabras, todo lo escrito por el autor británico está contenido de modo explícito en la adaptación realizada por Colleen Doran. De este hecho se desprende una sencilla pregunta: ¿es el cómic de Troll Bridge literatura? La respuesta es igual de clara y subyace en la misma pregunta: no, el cómic de Troll Bridge no es literatura, porque es un cómic.

Que la adaptación se haya llevado a cabo vertiendo el texto literario al completo no es, desde luego, baladí: la mera extensión del relato condiciona, de manera inevitable, la del cómic, que será directamente proporcional -en el nuevo medio- a la de aquel, la obra matriz. Esta, sin embargo, se encuentra ya subsumida en un medio semiótico mayor ${ }^{1}$, que la alberga en calidad de hiperónimo. Dentro del cómic la literatura se convierte en un hipónimo, y, como tal, no da -sino que adquiere- sus características formales esenciales: se transforma en un contenido dentro de un continente. El precitado carácter autónomo y autosuficiente de la literatura queda obliterado por la adaptación, y, en definitiva, deja de 
ser literatura per se. Aun con todo, no es menos cierto que sin "Troll Bridge" (el relato de Gaiman) no podría existir Troll Bridge (la adaptación de Doran). Incluso si en esta última no hubiera nada de texto o no se hubiera volcado todo el texto original, la relación seguiría siendo unidireccional en tanto en cuanto solo una de las dos obras (el cómic) necesita obligatoriamente de la otra (el relato) para existir ${ }^{2}$, pues de ella toma, como mínimo, la idea original.

A grandes rasgos, la relación entre el texto de Gaiman y la imagen (dibujo) de Doran en la adaptación puede entenderse como simbiótica, dado que ambos signos coexisten en una misma materia: el cómic de Troll Bridge. Esto no quiere decir, como bien señala Miodrag (2013, p. 124), que en el cómic se produzca una suerte de fusión indisociable entre texto e imagen y que no se dé una interacción entre ambos componentes de manera separada, sino simplemente que cohabitan el mismo medio. Ahora bien, ¿hay una de las partes que saque más provecho de esta convivencia que la otra? Para responder a esta segunda pregunta, resulta necesario delimitar cuáles son los motivos que llevan a adaptar un texto literario a cómic. Roche, Schmitt-Pitiot y Mitaine (2018, p. 19-21) subrayan tres razones fundamentales: la legitimidad; las motivaciones personales y políticas de quien adapta; y el interés económico y comercial. Con la primera se busca acreditar la capacidad expresiva del medio y validarlo como arte; la segunda resulta crucial en la medida en que, sin alguien con la voluntad de adaptar, no hay adaptación; y la tercera es acaso la más compleja, porque configura el entramado de producción de la inmensa mayoría de obras -adaptaciones o no- en la actualidad. El cómic de Troll Bridge no es una excepción, y es por tanto en este circuito comercial donde cabe contextualizarlo.

Juan Carlos Rodríguez (2013, p. 87) dijo que nacer -tanto más vivir- en un sistema capitalista es ser capitalista. Tanto el relato de Gaiman como la adaptación de Doran han sido producidos y consumidos en este marco socioeconómico, cuyo origen suele situarse -de manera muy aproximada- en el Renacimiento. Desde entonces, leer un libro (o, más recientemente, un cómic) se antoja un tipo de consumismo. Si bien hay un lapso de veintitrés años entre la publicación del cuento original (1993) y la del cómic (2006), las coordenadas sociológicas son en gran medida similares. No en vano, la propia ilustradora ha afirmado en una entrevista (Doran, 2016, 3:29-3:57) que ya hacia 1996 realizó una primera versión de la historia en ocho páginas, de la que después apenas quedó nada.

Pichois y Rousseau (1969, p. 84) propusieron determinar la "fortuna" de una obra en función de su "éxito" y de su "influencia", donde el primero es un factor cuantitativo (número de lectores o de objetos que ha inspirado) y la segunda es de naturaleza cualitativa. En una época en la que la imagen prepondera sobre la palabra (Roche, Schmitt-Pitiot y Mitaine, 2018, pp. 36-37), no resulta descabellado afirmar que la adaptación de Doran ha gozado de mayor éxito que el relato de Gaiman. Conviene, no obstante, hacer dos matizaciones al respecto: 1) Mientras que el cómic ha sido creado con conciencia de obra autónoma (con una edición propia, en exclusiva), la historia escrita formaba parte de una antología mayor de cuentos. Para hacer constar este hecho, que afecta a la recepción de una y otra obra, en el presente trabajo se aboga -como ya se comentó más arriba- por escribir el nombre del relato entre comillas ("Troll Bridge") y el de la adaptación a cómic en cursiva (Troll Bridge). 2) Aunque las redes sociales, desde su surgimiento en el siglo XXI, tienden a homogeneizar y amalgamar el arte en lo que Neil Postman (1985) lúcidamente denomi- 
nó "a sea of irrelevance", no es menos cierto que también aumentan su difusión. En este sentido, el éxito de Troll Bridge se ha visto potenciado por los nuevos medios digitales de comunicación, inexistentes cuando se publicó el texto original de Gaiman. Sin ir más lejos, la adaptación de Doran ocupó la lista de los cómics más vendidos de The New York Times en las fechas posteriores a su publicación original en 2016, a cargo de Dark Horse.

En suma, la simbiosis parece haber favorecido más al cómic que al relato, pero ¿se ha beneficiado este en algo al haber sido adaptado? En primera instancia resultaría lógico afirmar que sí, puesto que todo el texto está vertido en el cómic y, por lo tanto, leer la adaptación implica también leer el cuento original. Este planteamiento, sin embargo, arroja luces y sombras. En sentido estricto, la única manera de leer realmente el relato de Gaiman es acudiendo a él, no a una adaptación. Esta, si bien mantiene la totalidad del texto original, también introduce un añadido muy significativo: la imagen. Es un hecho científicamente demostrable que, al leer, el cerebro construye o recuerda objetos que se asemejan a los descritos. En efecto, en un estudio reciente sobre biología e inteligencia artificial (Rashkov, Bobe, Fastovets y Komarova, 2019) se ha logrado mostrar en una pantalla la imagen mental -tantas veces antes considerada una entelequia- que una persona crea al recibir un estímulo visual. Esto implica que, al leer un cómic (en el que se aporta una imagen fija), el cerebro no atiende solo al texto, sino también al dibujo. El proceso cerebral implicado en la decodificación de un texto no es el mismo en el caso de un cómic, ergo leer el texto de Gaiman en la adaptación de Doran no es leer el texto de Gaiman en sí. No puede negarse que la adaptación difunde y da a conocer el relato original, pero, en rigor, no es este último el que se está consumiendo.

Restan tan solo unas últimas puntualizaciones antes de analizar la intersemiótica de Troll Bridge. Por un lado, aquí se defenderá que cuando un texto está concebido de base para ser representado (en el caso del teatro), filmado (el cine), cantado (la música) o incluido en un videojuego -entre otros posibles medios-, su ontología es relacional. Esto implica que el texto carece de las ya mencionadas cualidades de autonomía y autosuficiencia y que, en puridad, no se trata de literatura per se. Este no es el caso de "Troll Bridge", un relato que no se escribió -en un principio- para ser trasladado a ningún otro medio distinto de la literatura. Que después, por algunas de las antedichas razones que motivan una adaptación, haya sido llevado al cómic no invalida su ontología literaria inicial.

Por otro lado, por motivos coyunturales, para el presente estudio se ha utilizado la versión española del cómic: El puente del troll (Planeta DeAgostini Cómics, 2019). Lejos de ser anecdótica, la utilización de este material conlleva una implicación importante de la que cabe advertir: al igual que la adaptación, la traducción cambia la obra original hasta el punto de ser otra distinta; no por casualidad, la adaptación ha sido definida como un tipo de traducción (Gaudreault y Groensteen, 1998). Esta cuestión no tiene demasiada incidencia en el tipo de análisis que se va a realizar, centrado más en la semiótica que en la variación textual entre distintas ediciones del cómic, pero es importante subrayarla como caución previa a la investigación. 


\section{Cruzando El puente del troll}

"El puente del troll", de Neil Gaiman, es una fábula narrada en primera persona por el protagonista, Jack, que cuenta su propia historia a lo largo de tres periodos de su vida: infancia, adolescencia y edad adulta. En cada una de esas etapas, se encuentra con un troll debajo de un puente que ansía comerse su vida. En su primer encuentro con la criatura, Jack, que tenía entonces siete años y la cabeza llena de fantasías, logra escapar al acordar con el troll que él mismo volverá a buscarlo en el futuro, cuando haya crecido y sea más apetitoso. En el segundo, un Jack de quince años, ya adolescente, se para bajo el puente con Louise, su primer amor. Al comenzar a besarse, el troll aparece de nuevo dispuesto a devorar a Jack, y este le ofrece a la chica en su lugar al tiempo que insiste en volver cuando sea mayor. En la época del tercer y último encuentro, Jack es adulto y trabaja para una de las mayores discográfica de Londres. Al engañar en reiteradas ocasiones a su mujer, Eleanora, esta se marcha de casa y Jack queda solo, herido por sus propias acciones. Durante un paseo termina llegando una vez más al puente, donde el troll devora su vida y se hace pasar por él. Jack da a entender que él mismo es ahora el troll, que, desde las sombras, observa a la gente pasar por el puente.

Toda la diégesis es analéptica (retrospectiva) excepto al final, cuando Jack ya ha quedado convertido en el troll; solo entonces el narrador habla en presente. Acaso como toda gran fábula, "Troll Bridge" es una historia aparentemente sencilla, no demasiado extensa, pero muy rica en matices e ideas. Como apuntan Luque (2019, p. 1) o Slabbert (2009, p. 73), se trata de una nueva versión de la fábula noruega de Los tres machos cabríos Gruff, en la que tres cabritos intentan cruzar de uno en uno un puente donde los espera un troll con intención de comérselos. El primero dice al ser mitológico que aguarde mejor la llegada de su segundo hermano, más grande y suculento. Este hace lo propio remitiendo al tercer cabrito, que, más fuerte que ninguno, acomete contra el troll y lo lanza al río.

A medida que el personaje de "Troll Bridge" crece, también su entorno va cambiando. Al comienzo, la historia se ambienta en una pequeña ciudad cerca de Londres, en la que acaban de retirar las vías del tren. El paisaje es completamente rural y los árboles, el agua o la luz son elementos constantes. Con el tiempo, sin embargo, el entorno se va oscureciendo y se vuelve cada más urbano y difuso, en consonancia con el estado de ánimo de Jack. Este cambio progresivo dota al relato de policromatismo y múltiples capas semánticas, que permitirán estudiarlo desde diversos puntos de vista. Quizás uno de los más provechosos, que se considerará aquí en el caso del cómic de Colleen Doran, es el de la teoría del afecto, esto es, qué emociones subyacen en la obra y cómo responde a ellas el lector. No por casualidad, la ilustradora estadounidense ha asegurado que quería contar una historia sobre la naturaleza del tiempo y la diferente percepción que se tiene de él en las zonas rurales y las urbanas (Doran, 2016, p. 0:27-1:17). Este deseo posiblemente motivó la adaptación del cuento de Gaiman, que ya había trabajado con ella en numerosas ocasiones y sabía "how good she is" (palabras del autor británico recogidas por Calvin Reid, 2015).

Un último punto importante de carácter general concierne a la categoría estética del relato y, por extensión, a la del cómic: ¿es “Troll Bridge” un cuento fantástico o de realismo mágico? Aunque no pocos críticos parecen haberse decantado con rotundidad por una u otra, en este trabajo la propuesta de categorización será algo más dual. David Roas (2019, pp. 
57-58), cuya teoría del fantástico resulta operatoria tanto para la literatura como para el cómic (entre otras artes), señala el grado de naturalización de lo sobrenatural como rasgo diferenciador: mientras que en el realismo mágico lo imposible es asumido con normalidad en el mundo ficcional, en lo fantástico se produce un enfrentamiento entre lo posible y lo imposible que genera de modo inevitable un efecto de miedo metafísico. La idoneidad de este planteamiento $-y$, en realidad, de cualquiera- encuentra su mayor obstáculo en la hermenéutica, esto es, en cómo interpretar ciertos aspectos de la obra objeto de análisis. El caso de "Troll Bridge" resulta problemático en este sentido porque no es posible determinar con facilidad -como sí ocurre en otros textos- cuán naturalizado está realmente el principal elemento fantástico que aparece: el troll. Aunque por sí solo este ser mitológico constituya un rasgo inequívocamente fantástico, en el ecosistema del cuento hay indicadores que sugieren una neutralización del mismo como tal: el protagonista siente miedo ante la presencia -literal o figurada- de la criatura, ¿pero acaso no toma su existencia con naturalidad hasta el punto de negociar con él y de verlo venir en los encuentros posteriores? ¿acaso el entenderlo como una manifestación de sus propios miedos, en clave alegórica, no potencia más los presupuestos del realismo mágico que los de lo fantástico? La ambivalencia parece inherente al relato, que desde luego también puede entenderse como una transgresión de lo real a partir de la irrupción del troll, que incluso parece suplantar de modo corpóreo a Jack al final. A tenor de lo aducido, en este trabajo se aboga por legitimar "Troll Bridge" como oscilante entre una y otra categoría, sin que esto suponga una deficiencia en la estructura de la obra o en la exégesis del transductor.

Valoraciones análogas pueden hacerse de la adaptación a cómic de Doran, El puente del troll, cuyos temas, personajes y escenarios son en esencia los mismos. No obstante, al tratarse de un medio semiótico diferente se produce lo que Maaheen Ahmed refiere como "confrontation transsémiotique", esto es, "the problems raised during transpositions between media" (232-33). Como ella misma destaca, una comparación entre el texto literario y el cómic puede esclarecer el fenómeno de la transmédiatisation, puesto que los cambios realizados en la adaptación reflejan la relación entre uno y otro medio y, sobre todo, los recursos del cómic para transferir el contenido de palabras a imágenes. Con este propósito, se dedican las líneas que siguen a estudiar la cristalización de los elementos originales en la adaptación de Colleen Doran, sin que esto suponga en absoluto la concepción de ganancias $y / o$ pérdidas en la equidistancia entre dos medios que, simplemente, son distintos. Un buen punto de partida es la precitada teoría del afecto (affect theory), cuyo origen se atribuye al psicólogo estadounidense Silvan Tomkins en su obra Affect Imagery Consciousness (1962). Utilizado en crítica literaria con más o menos fortuna, este sistema permite categorizar las emociones contenidas en una obra a través -normalmente, aunque no solo- de sus actantes. A partir de ahí, puede evaluarse la respuesta emocional que el lector presenta ante los distintos estímulos narrativos. Sin ir más lejos, un estudio de Keith Oatley (2016, pp. 168-69) sugiere que leer ficción desarrolla la empatía y la capacidad de las personas para vivir en sociedad. Conviene, eso sí, puntualizar que los sentimientos y los consiguientes pensamientos - pues los unos no son posibles sin los otros-se adscriben al $\mathrm{M}_{2}$ (siguiendo de nuevo la Teoría de la Literatura desde el Materialismo Filosófico), es decir, a la materia psicológica, la psique, el ánimo. Las emociones no tienen validez teórica 
hasta que no son organizadas crítica y racionalmente en el $\mathrm{M}_{3}$ o materia terciogenérica: la ciencia propiamente dicha (Maestro, 2014, p. 50).

En "Troll Bridge", Jack pasa de una infancia de viveza, ilusión y fantasía a una adolescencia y una posterior edad adulta a cada cual más oscuras. En palabras de Slabbert (2009, p. 75), "Jack's ontological inquiry is fuelled by the loneliness of a life [...] which has become stagnant amongst the frivolous, harsh and dehumanized constructions of contemporary consumer society". Esta encrucijada del protagonista es, en realidad, una sensación que la mayoría de seres humanos experimentan en algún momento a lo largo de sus vidas a medida que entran en contacto con el mundo adulto. La sociedad capitalista contemporánea acrecienta ciertamente este dilema, que deja tres opciones a la persona: renovarse y vivir, suicidarse y morir (el suicidio, dijo Sartre, es una posibilidad ante el absurdo [Cholbi, 2017: 3.9]) o, como le termina sucediendo al protagonista del cuento, morir en vida. Así lo expresa Luque (2019, p. 2), que ubica al diablo mismo -el troll, en el cuento- en el "cruce de caminos" por el que pasa Jack:

Como él, todas las personas que, por la educación recibida, la clase social o su entorno familiar, han querido ocultar su no normatividad, su divergencia del plan socialmente predefinido, llegan a sufrir crisis de identidad, problemas de salud mental e incluso dudas respecto a su humanidad y a si merecen seguir viviendo. $\mathrm{Y}$ es en la forma de afrontar estos problemas donde encontramos realmente al diablo en el cruce de caminos. Algunas de ellas optan por decisiones extremas y otras consiguen liberarse de todos sus yugos y salen adelante. Pero hay quienes se quedan en un punto intermedio, en la negación, la no auto aceptación, y entonces viven atrapados bajo un puente húmedo, sucio y oculto, enfrentados a su demonio mientras escuchan las vidas del resto pasar por encima de sus cabezas.

Esta problemática está íntimamente relacionada con el llamado síndrome de Peter Pan, un término aceptado en la psicología popular desde la publicación de The Peter Pan Syndrome: Men Who Have Never Grown Up (1983), de Dan Kiley, que hace referencia al miedo a crecer y aceptar los roles propios de la adultez. En particular, a propósito del cuento de Gaiman, Ivan Čipkár publicó en 2019 un estudio partiendo de la ya mencionada teoría del afecto. En este, constata que las personas que mayor respuesta emocional presentaron ante la lectura del cuento fueron aquellas que habían atravesado por situaciones similares a las del protagonista en algún momento de sus vidas, es decir, que se sentían identificadas con él. Al final de la historia, se hace evidente que el autor británico apela de forma directa al lector para implicarlo emocionalmente. Justo al final, Jack deja de hablar en primera persona (como hace el resto del relato) y se dirige a una segunda persona del plural: "Mi único deseo es permanecer en la oscuridad que reina bajo el arco. Desde aquí os oigo a todos. Estáis fuera, y no hacéis más que merodear por mi puente" (la cita es del cómic, en traducción de José Torralba). No cabe duda de que el personaje acaba enunciando estas palabras no solo para satisfacer la verosimilitud interna de la ficción, sino principalmente para moralizar, de manera metaléptica, al lector de la obra. 


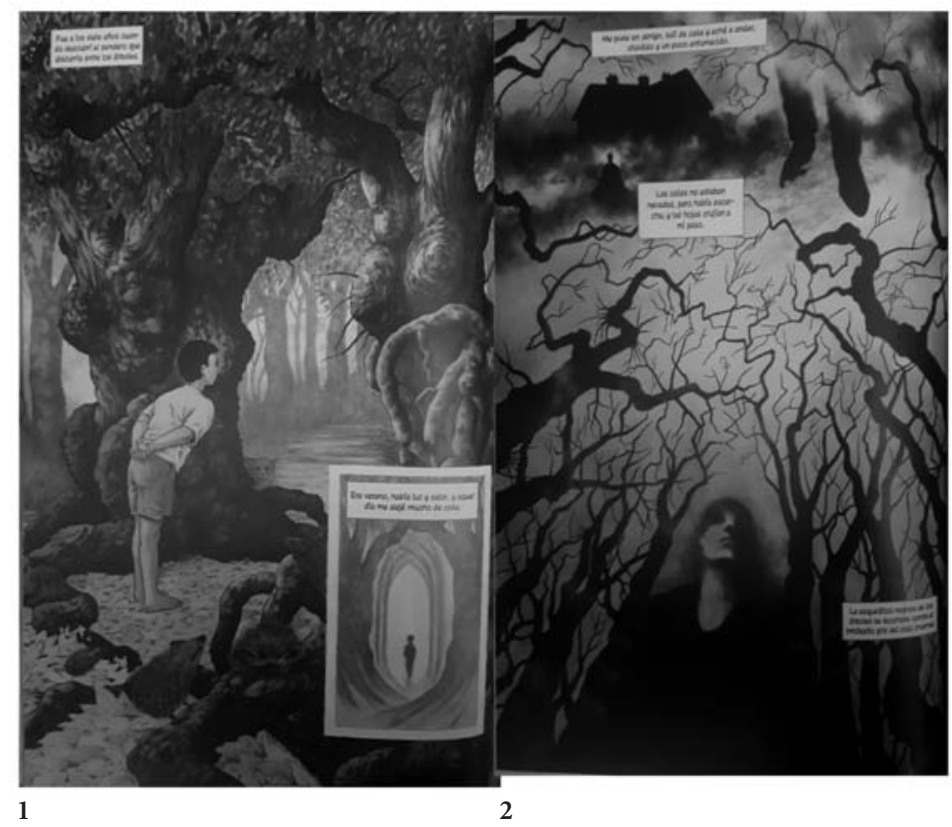

Figuras 1 y 2, en las que se observa el contraste entre el dibujo utilizado para plasmar la infancia animada -y, aún, misteriosa- del niño y el empleado para su etapa adulta, mucho más sombrío y difuso. Fuente: imágenes propias extraídas de El puente del Troll @Neil Gaiman (c) Colleen Doran (C Planeta DeAgostini Cómics. 2019.

La pregunta ahora es: ¿qué recursos visuales utiliza Colleen Doran en la adaptación para transmitir todas estas emociones al nuevo receptor del cómic? La artista ha afirmado que quería crear una extraña mezcla entre la perspectiva infantil de un niño y la sensibilidad de un adulto, impregnando la obra de una sensación de miedo desde el comienzo mismo (Doran, 2016, p. 1:58-2:34). El efecto más inmediato del nuevo medio es la denotación: mientras que en una narración exclusivamente textual-que no verbal-el lector suele estar sometido a una mayor carga connotativa, con el dibujo se produce una desambiguación de lo descrito textualmente. Este incremento denotativo del cómic se amplifica con el uso de color, que, frente al blanco y negro, aporta aún más detalles de la realidad ficcional. Esto no niega la existencia de un filtro entre la obra y la realidad del receptor (todo medio semiótico es un filtro), sino que simplemente anula la ambigüedad descriptiva y obliga a connotar por otras vías.

Así pues, Colleen Doran se sirve de la paleta cromática para establecer un contraste entre la infancia de Jack y su etapa adulta (véanse las Figuras 1 y 2). En las primeras veinte páginas 
del cómic priman los colores cálidos y luminosos, acordes con el entorno natural que el niño frecuenta. Asimismo, las formas tienen un trazo preciso y delimitado, que permite distinguirlas con claridad. Neil Gaiman ha destacado precisamente el estilo colorido de la artista: "She showed me an unusual style [done with color pencils] that isn't like classic comics. Her pencils are wonderful, layered full-color drawings. They're subversive, more like children's book illustrations from 50 years ago" (palabras recogidas por Calvin Reid, 2015). Las formas definidas se mantienen en las páginas que narran la adolescencia del personaje, pero en esta etapa los colores son ya más pálidos; la mera vestimenta de Jack, negra, contrasta con la camiseta amarilla y el pantalón azul claro de su puericia. La ilustradora, como cualquier adaptador que trabaja en un medio visual, ha tenido que tomar decisiones que muestran -más que describen o sugieren- cómo es el personaje. Ella misma comenta en la entrevista que el dibujo que había realizado en un principio para la primera etapa de Jack era muy abstracto, por lo que decidió rehacerlo para hacer más palpable la sensibilidad infantil (Doran, 2016, p. 4:11-4:34). En el último tramo de la historia, cuando el personaje es ya adulto, los tonos son fríos y transmiten una sensación fúnebre. Doran juega con el claroscuro y a menudo evita mostrar el rostro de Jack. En consonancia, las formas están también mucho más difuminadas, lo que refuerza la sensación de indefinición y soledad que caracteriza al protagonista antes de ser devorado por el troll. Doran ha sabido unificar colores poco habituales en el cómic para transponer $-\mathrm{y}$, acaso, magnificar- las emociones que afloran con el cuento escrito.

Por otro lado, el troll es un elemento que plantea varios problemas a la hora de trasladarlo al cómic. Más allá de la comentada pérdida de connotación al representarlo mediante el dibujo, hay que considerar su carácter metafórico. El relato original de Gaiman permite una lectura alegórica completa en la que el troll no es un ente tangible, sino una mera alusión simbólica a los miedos e inseguridades del protagonista (y, por extensión, al lector). No en vano, del cuento se desprende la pregunta de si el carácter de Jack se enturbia a raíz de un encuentro real con el troll (físico) o si ya tenía el germen desde el principio y el relato simplemente metaforiza su declive progresivo. Así pues, ¿cómo mantienen el cómic y, en particular, la artista en la adaptación la posibilidad de realizar esta segunda lectura de carácter figurado?

Cuando Doran dibuja al troll (véase Figura 3), lógicamente está creando un referente ficcional que se presupone corpóreo -o, cuando menos, real- en la medida en que el lector lo percibe visualmente en la página. ¿Quiere esto decir que el comic está semióticamente imposibilitado para crear sus propias metáforas? De entrada, conviene tener en cuenta las palabras de Elisabeth El Refaie (2003, p. 90), que aboga por no asumir "that every visual form has an exact verbal equivalent and vice versa". Aun con todo, puede argüirse que el cómic produce lo que Gasca y Gubern (1988, p. 312) recogieron como metáfora visual: un símbolo que, desde la imagen, genera un efecto igualmente alegórico. A la célebre frase the medium is the message, de Marshall McLuhan, siguió the medium is the metaphor, del ya citado Neil Postman. En el caso de un cómic, esta metáfora visual-sintagma aparente pero no necesariamente oximorónico- precisa de un esfuerzo mayor por parte del receptor, que ha de aceptar que lo que ve, incluso si plasmado mediante el dibujo, podría no ser más que una representación figurada. Si el lector de cómics logra hacer esto, la metáfora en los mismos debe ser definitivamente posible. Al pacto de ficción que se exige a todo receptor de lo 


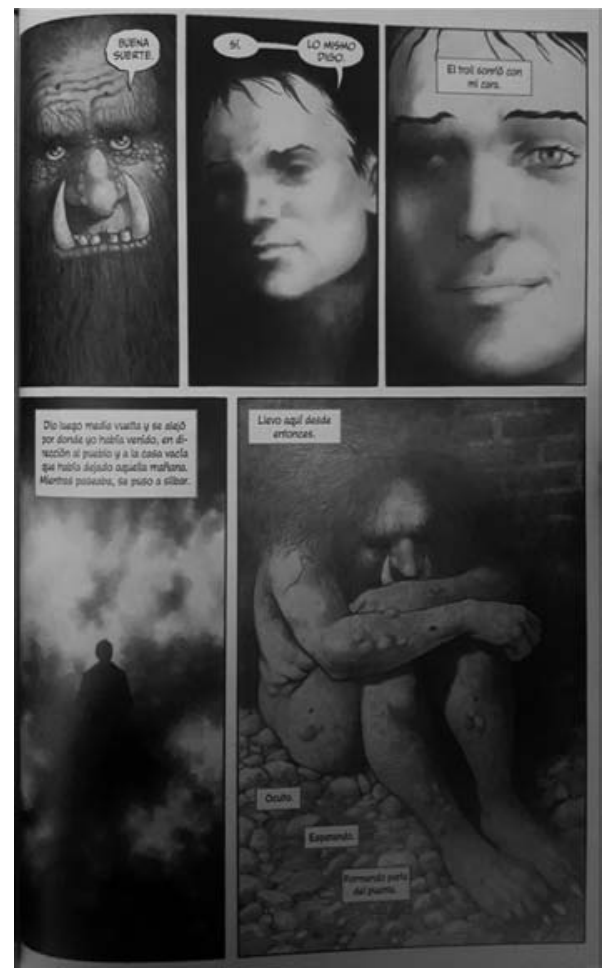

Figura 3. Penúltima página de El puente del troll, en la que se aprecia la representación del troll (ya intercambiado por Jack, que lo mira con ojos verdes) por parte de Colleen Doran. Fuente: imagen propia extraída de El puente del Troll @ Neil Gaiman () Colleen Doran (C) Planeta DeAgostini Cómics. 2019

fantástico -o del realismo mágico-, en el cómic hay que añadir lo que podría denominarse el pacto de la metáfora visual. Al fin y al cabo, la metáfora existe en el momento en que, a partir de un estímulo previo (textual, visual, sonoro), el cerebro la reconoce como tal. En la Figura 3 se observa, además, la sonrisa que el troll brinda a Jack una vez se ha convertido en él (ya sea en sentido real o figurado). En el relato original, Gaiman no aporta en ningún momento la información del color de ojos para ninguno de los dos personajes. En cambio, Doran, obligada una vez más a desambiguar dicho rasgo en cuanto que ilustradora, opta por dar un color azul a los ojos de Jack (que, en la Figura 3, es ya el troll) y un tono verde a los de la criatura, que ríe burlonamente. Cabe aquí señalar lo que Miodrag (2013, p. 130) llama "juxtaposition", que define como una "non-interactive co-presence" entre lo visual y lo verbal. La propia Colleen Doran (2016, p. 5:10-5:52) menciona la yuxtaposición a propósito de combinar imágenes y texto de manera que se mantenga cierto grado de sugerencia en el cómic; la figura 1 de este trabajo - una de las páginas favoritas de la artista- es paradigmática al respecto. 
Todo esto implica que el cómic, aunque quizás más restringido que la literatura para plasmar ciertos elementos, goza en cambio de determinadas capacidades expresivas de las que un texto no dispone. Considérese, por último, el cambio de página, que no tiene ninguna significación en particular en una obra escrita pero que, en el cómic, puede ser la antesala de un giro argumental o momento álgido. Sin ir más lejos, cuando el lector pasa la penúltima página de El puente del troll (Figura 3) se encuentra con una última splash page (esto es, aquella que consta de una sola imagen o panel) en la que se ve de nuevo la última viñeta de la página anterior, esta vez más distanciada con la intención de mostrar la situación final en la que queda el protagonista al término de la historia.

\section{Conclusiones}

Con el cómic El puente del troll como principal objeto de estudio, este trabajo se ha dividido en dos grandes bloques. En el primero, se ha intentado proporcionar algunas claves sobre cómo analizar una adaptación realizada de la literatura al cómic. Así, se aboga por separar claramente ambas artes en la medida en que se trata de dos medios semióticos distintos. El caso concreto de El puente del troll, en el que la ilustradora (Colleen Doran) vierte el texto original de Neil Gaiman de manera íntegra, resulta elocuente de cómo el cómic tiene la capacidad semiótica para albergar la literatura como si de un hiperónimo se tratara, al tiempo que añade un signo visual.

Este, sin embargo, como se ha tratado de dilucidar en el segundo bloque de la investigación, no siempre permite la transposición correlativa de los elementos de uno a otro medio. Por ejemplo, la metáfora visual, aunque posible en el cómic, requiere un esfuerzo mayor por parte del receptor, que ha de convencerse de que lo que ve puede tener un sentido figurado. Sin esta actitud, realizar una lectura alegórica de El puente del troll resulta casi inviable por más que la historia, personajes y escenarios la permitan. Por otro lado, en el estudio de caso llevado a cabo se constata que Doran es capaz de reflejar visualmente las emociones objetivadas en la ficción, y que alcanzan también al receptor. Para ello, la artista se sirve de recursos tales como la paleta cromática, que utiliza en consonancia con el tono del cuento en cada momento; o la yuxtaposición de elementos visuales y verbales, que acaso intensifica lo narrado exclusivamente mediante palabras en el texto original. La transposición total de los materiales al nuevo medio no es en modo alguno posible en forma, pero quizás sí en esencia.

En definitiva, la adaptación forma hoy parte de un entramado capitalista en el que la imagen parece preponderar sobre la palabra. En este contexto, puede decirse que la adaptación a cómic de El puente del troll ha tenido una mayor recepción que el relato de Gaiman. Este, no obstante, goza de un estatus de obra influyente en la medida en que ha motivado una adaptación gráfica. Aunque, en rigor, consumir el cómic no equivale a leer el texto por más que este haya sido trasladado en su totalidad, cabe afirmar que también la obra del escritor británico se ve beneficiada con la adaptación. Más aún cuando esta es producto de un afán creativo sincero que nace al calor de una colaboración ya habitual entre ambos artistas, Neil Gaiman y Colleen Doran. 


\section{Notas}

1. Con "medio semiótico mayor" se alude a la mayor cantidad de signos que contiene el medio. El cómic, por funcionar con la imagen, es semióticamente más rico que la literatura (lo que no se traduce necesariamente, huelga decir, en mayor connotación o calidad de la obra, entre otros aspectos).

2. Por existir se entiende aquí el haber sido concebida y tener entidad física, esto es, el $M_{1}$ según la Teoría de la Literatura desde el Materialismo Filosófico de Maestro (2014, p. 50). Esta fisicidad puede darse tanto en papel como en un soporte electrónico.

\section{Referencias bibliográficas}

Ahmed, M. (2016). Openness of Comics. Generating Meaning within Flexible Structures. Mississippi: University Press of Mississippi.

Cholbi, M. (2017). Suicide. En Stanford Encyclopedia of Philosophy. Obtenida el 1 de abril de 2020, de https://plato.stanford.edu/entries/suicide/.

Čipkár, I. (2019). Enjoy Your Trials: Emotions of Reader-response in Neil Gaiman's 'Troll Bridge. PsyArt, 23, 105-137.

Doležel, L. (1986). Semiotics of Literary Communication. Strumenti Critici, 1, 5-48.

Doran, C. (2016). NYCC: TMS Speaks to Illustrator Colleen Doran of Neil Gaiman's TROLL BRIDGE for Dark Horse Comics. En Youtube. Obtenida el 30 de marzo de 2020, de https://www.youtube.com/watch?v=Eku4eH3XiAc.

El Refaie, E. (2003). Understanding visual metaphor: the example of newspaper cartoons. Visual Communication, 2(1), 75-95.

Gaiman, N. y Doran, C. (2019). El puente del troll. Barcelona: Planeta DeAgostini Cómics. Gasca, L. y Gubern, R. (1988). El discurso del cómic. Madrid: Cátedra.

Gaudreault, A. y Groensteen, T., eds. (1998). La Transécriture. Pour une théorie de l'adaptation. Littérature, cinéma, bande dessinée, théâtre, clip. Québec / Angoulême: Éditions Nota Bene y Centre national de la bande dessinée et de l'image.

Hutcheon, L. (2006). A Theory of Adaptation. Londres: Routledge.

Maestro, J. G. (2014). Contra las musas de la ira: el materialismo filosófico como teoría de la literatura. Asturias: Pentalfa.

Miodrag, H. (2013). Comics and Language. Reimagining Critical Discourse on the Form. Mississippi: University Press of Mississippi.

Oatley, K. (2016). Fiction: Simulation of Social Worlds. Trends in Cognitive Sciences, 20(8), 618-628.

Pichois, C. y Rousseau, A. M. (1969). La literatura comparada. Barcelona: Gredos.

Postman, N. (2005). Amusing Ourselves to Death: Public Discourse in the Age of Show Business. Londres: Penguin Books.

Rashkov, G.; Bobe, A.; Fastovets, D. y Komarova, M. (2019). Natural image reconstruction from brain waves: a novel visual BCI system with native feedback. En bioRxiv. Obtenida el 31 de marzo de 2020, de https://www.biorxiv.org/content/10.1101/787101v2.full.pdf. 
Reid, C. (2015). Dark Horse to Publish Graphic Versions of Neil Gaiman Short Stories. En Publishers Weekly. Obtenida el 1 de abril de 2020, de https://www.publishersweekly. $\mathrm{com} / \mathrm{pw} /$ by-topic/industry-news/comics/article/68953-dark-horse-to-publish-graphicversions-of-neil-gaiman-short-stories.html.

Roas, D. (2019). Tras los límites de lo real. Una definición de lo fantástico. Madrid: Páginas de Espuma.

Roche, D.; Schmitt-Pitiot, I. y Mitaine, B. (2018). Comics and Adaptation. En B. Mitaine, D. Roche y I. Schmitt-Pitiot (Eds.), Introduction. Adapting Adaptation Studies to Comic Studies (11-56). Mississippi: University Press of Mississippi.

Rodríguez, J. C. (2013). Entrevista a Juan Carlos Rodríguez, por David Becerra Mayor. Youkali: revista crítica de las artes y el pensamiento, 15, 85-92.

Slabbert, M. (2009). Fairy Tales Reimagined. Essays on New Retellings. En Susan Redington Bobby (Ed.), Inventions and Transformations. Imagining New Worlds in the Stories of Neil Gaiman (68-84). Carolina del Norte: McFarland \& Company Inc., Publishers.

The New York Times (2016). Best Sellers: Hardcover Graphic Books. En The New York Times. Obtenida el 31 de marzo de 2020, de https://www.nytimes.com/books/best-sellers /2016/11/20/hardcover-graphic-books/.

Luque, A. (2019). El diablo en el cruce de caminos. El puente del troll, 1-2. Barcelona: Planeta DeAgostini Cómics.

Waller, C. (2016). Troll Bridge Review. En Wethenerdy. Obtenida el 31 de marzo de 2020, de https://wethenerdy.com/troll-bridge-review/.

\begin{abstract}
In this work, the adaptation from literature into comic is studied taking the specific case of Troll Bridge (a short story by Neil Gaiman that Colleen Doran has illustrated more than twenty years after the publication of the former) as a point of departure. In the first place, the fact of adaptation is contextualized as part of a socioeconomic framework in which both works (the adapted and the adaptation) feed each other. Special emphasis is put, however, on differentiating the features of one medium and those of the other even when the comic by Doran entirely translates the original text by Gaiman. In the second place, consideration is given to the intersemiotic characteristics that derive from thee adaptation, in order to examine the transposition of the different elements from one medium into the other. In this way, special attention is paid to the juxtaposition of word and image, to metaphor and, mainly, to the transmission of emotions in the frame of an allegorical fable. As a conclusion, it is argued that an absolute semiotic change is inviable insomuch as they are two different media, although the constituents of the fiction (story, characters, settings) are essentially the same.
\end{abstract}

Keywords: Adaptation - Intersemiotics - Fantastic - Emotions - Metaphor.

Resumo: Este trabalho estuda a adaptação da literatura aos quadrinhos com base no caso específico de The Troll Bridge, uma história de Neil Gaiman que Colleen Doran ilustrou 
há mais de vinte anos, após a publicação do primeiro. Em primeiro lugar, o fenômeno da adaptação é contextualizado como parte de uma estrutura socioeconômica na qual ambas as produções (adaptada e adaptação) se retroalimentam. Dá-se, não obstante, ênfase à distinção entre as características de um meio e as do outro, mesmo quando os quadrinhos de Doran vertem o texto original de Gaiman em sua totalidade. Em segundo lugar, atentase especialmente às características intersemióticas que emergem da adaptação, a fim de examinar a transposição dos diferentes elementos de um meio a outro. Assim, prioriza-se a justaposição entre palavra e imagem, a metáfora e, sobretudo, a transmissão de emoções no quadro de uma fábula alegórica. Conclui-se que a transferência semiótica total é inviável na medida em que envolve duas mídias diferentes, embora os constituintes da ficção (história, personagens, cenários) sejam essencialmente os mesmos.

Palavras chave: Adaptação - Intersemiótica - Fantástico - Emoções - Metáfora.

[Resúmenes en inglés y portugués en la página ] 